\title{
Paradigmas económicos corroídos ${ }^{1}$ Corrupted economic paradigms
}

Journal of Economic Literature (JEL): F02, O11, P16, R2

Palabras clave: Orden económico internacional Análisis macroeconómico del desarrollo Economía política del capitalismo Análisis de las economías locales

\section{Keywords:} International Economic Order Macroeconomic Analysis of Economic Development Political Economy of Capitalism Household Analysis

Fecha de recepción: 27 de enero de 2017 Fecha de aceptación: 21 de abril de 2017

ECONOMÍAunam vol. 14, núm. 41, mayo-agosto, 2017

\section{Resumen}

Se hace una revisión de la situación actual David Ibarra
Doctor Honoris Causa por la UNAM
"dibarra@prodigy.net.mx» donde la crisis y la desigualdad generalizada marcan la obsolescencia del orden económico mundial. Por ello es urgente emprender la búsqueda de un mejor acomodo político entre naciones y entre las capas sociales al interior de las mismas a fin de lograr la conjugación adecuada de libertades, democracia y bienestar. En ese sentido habrá que evaluar la influencia de los sistemas tributarios, los mercados laborales, la distribución del ingreso y el papel de nuevos protagonistas en el diseño de políticas públicas de alcance mundial. Asimismo, se evalúa la situación de México frente a los posibles cambios de políticas norteamericanas. Finalmente se advierte que cuando el desarrollo se esfuma, conviene que Estado y mercado dejen de ser excluyentes para tornarse complementarios. En México con una política industrial selectiva y un sólido compromiso empresarial, se podrá retomar el crecimiento, así como subsanar cuestiones sociales con frecuencia relegadas por las reglas de la globalización.

\section{Abstract}

A review is made of the current situation where the crisis and the widespread inequality show the obsolescence of the world economic order. It is therefore urgent to search for better political accommodations among nations and among social groups within the countries in order to achieve an adequate combination of liberties, democracy and well-being. It is needed to revaluate the tax systems, labor markets arrangements, income distribution and the role of new players in the world policies. Likewise, the situation of Mexico is taken up against possible changes in US policies. Moreover, since growth fades in Mexico, state and markets will need to complement efforts and implement a selective industrial policy with strong corporate commitments, as well as tackling social issues, often relegated.

(C) 2017 Universidad Nacional Autónoma de México, Facultad de Economía. Este es un artículo Open Access bajo la licencia CC BY-NC-ND (http://creativecommons. org/licenses/by-nc-nd/4.0/). 


\section{Preámbulo}

Vivimos una época en que el mundo y nuestro país demandan con urgencia del reordenamiento

de ideas, de las normas económicas, sociopolíticas y de modelos que ya incumplen la promesa de mejorar y hacerlo ordenada, parejamente, el bienestar de las poblaciones. La prolongadísima crisis mundial que hizo erupción en 2007-2008 y la desigualdad generalizada son manifestación innegable de la inadecuación del orden económico internacional que hace imperativo emprender la búsqueda de un mejor acomodo político entre las naciones y entre las diversas capas sociales al interior de los países. Poco a poco se obstruyen o se hacen inestables las avenidas al progreso que se habían diseñado desde hace tiempo o desde hace poco para lograr la conjugación armoniosa de libertades, democracia y bienestar. Quizás estamos situados en el tránsito hacia un nuevo régimen de política económica de carácter universal que traerá consigo trastornos antes de ofrecer a plenitud sus beneficios.

\section{Límites y cambios paradigmáticos}

\section{a) El orden mundial}

Desde el término de la Segunda Guerra Mundial, Estados Unidos se constituyó en líder del orden mundial lo mismo en términos de garantizar la seguridad del Mundo Occidental que de cuidar y promover un orden económico global basado en la apertura de las economías a las corrientes comerciales o financieras y en el manejo de gobiernos de dimensiones pequeñas. Ese andamiaje posiblemente sufrirá alteraciones y acotamientos frente a la evolución de la realidad y de los pronunciamientos o demandas recientes de los países líderes. El propio presidente de Estados Unidos ya ha pedido a Europa, Japón y otros países que compartan el financiamiento de los gastos comunes de defensa, quizás con debilitamiento de la Organización del Atlántico del Norte (OTAN). Asimismo, ha expresado y tomado acciones con esbozos de proteccionismo frente a la política tradicional de fronteras abiertas. Y, en su primer presupuesto se perfila desgravación impositiva a la renta, ${ }^{1}$ menor ayuda al desarrollo y a la protección del medio ambiente. Independientemente de su validez intrínseca,

1 A reserva de que el Congreso Norteamericano apruebe la propuesta del Poder Ejecutivo, ésta parece consistir en bajar la tasa impositiva del Impuesto sobre la Renta a las Empresas de 35\% actual a 15\%; rebajar la carga máxima de las personas ricas de 39 a 35\%; reducir de siete a tres los tramos fiscales de la progresividad del gravamen a la renta; suprimir el impuesto a las herencias; eliminar buena parte de las deducciones impositivas y favorecer la repatriación de capitales. En conjunto, el esquema esbozado favorecería la concentración del ingreso y la afluencia de capitales hacia los Estados Unidos, contrariando la corrección proyectada de la balanza de pagos y de las tasas de interés de la Reserva Federal. Eso mismo, acrecentaría el déficit gubernamental norteamericano a menos que milagrosamente se valide la teoría de Laffer, donde se postula que el crecimiento de la economía inducido por los menores gravámenes, compensarían y aún producirían excedentes en las arcas fiscales. A escala internacional, la iniciativa alentaría inestabilidad en los mercados cambiarios y, a más largo término, presiones fiscales competitivas que moverán regresivamente la estructura de los regímenes tributarios de los países. A título ilus- 
la nueva postura norteamericana ha creado incertidumbre mundial sobre una posible vuelta al aislacionismo o al proteccionismo. Todo eso, quizás induzca más adelante configuraciones defensivas y la formación de nuevos liderazgos o alianzas que llenen los huecos que se vayan creando en el ámbito internacional (Patrick, S. 2017, Nye, J., 2017, Anderson, P., 2015, Zakaria, F., 2016).

Hasta hace poco en aras de los mercados libres, el neoliberalismo había hecho a un lado las cuestiones distributivas y podado mucho de las facultades desarrollistas de las políticas hacendarias para centrar la macroeconomía en el monetarismo de bancos centrales preocupados casi exclusivamente en combatir la inflación e inmunes o casi inmunes a las vicisitudes políticas de los países. En términos abstractos de equidad se sostenía que la libertad plena de mercados, esto es, después de eliminar todas las fuentes de distorsión económica-como tarifas, impuestos y sindicatos- llevaría a que cada persona reciba en justicia lo que merece de acuerdo con su contribución al producto común.2

Sin embargo, esa visión resultó por lo menos parcialmente infundada en la realidad al incumplirse el supuesto de la capacidad autocorrectora de los mercados en sostener un crecimiento y una distribución aceptables. Más adelante fueron quedando en entredicho algunas ventajas del acotamiento progresivo de las funciones del Estado, de la liberación comercial o de la fe en que el intercambio y la inversión foránea impulsarían el crecimiento de todos. El mayor logro histórico fue el abatimiento general de la inflación, pero las frecuentes crisis y la honda recesión de 2008, mostraron la fragilidad intrínseca de la organización de los mercados, siempre necesitada del intervencionismo estatal para corregir desviaciones peligrosas y señalar direcciones estables al desarrollo. Experiencias históricas repetidas demuestran que los sistemas mercantiles son propensos a la inestabilidad, a sufrir vaivenes riesgosos o a caer en la especulación, mientras los rescates resultantes requieren

Las estrategias de crecimiento hacia afuera como sostén del desarrollo comienzan a manifestar debilidades usualmente del respaldo de los gobiernos (Minsky, H., 1986, Williamson, J., 1990, Ha-Joon, Ch., 2002, Ibarra, D., 2006, Bresser-Pereira, L., et al., 1993, Streeck, W., 2014).

Así ha ocurrido con los recientes salvamentos bancarios o industriales en Estados Unidos, Europa o México. Por otro lado, el principal expediente de combatir la crisis sigue siendo tasas de interés bajas - como medio de promover el crédito y el gasto- complementados, si necesario, con la inyección de liquidez por la vía de la compra de activos privados o públicos por los bancos centrales, con la esperanza de reactivar a las economías. Hoy por hoy, bajar las tasas de interés y aún hacerlas negativas, es el mecanismo sustituto a la inflación para reducir el peso del servicio de la deuda a los sectores público y privado. Pero al hacerlo se desalienta el ahorro y quizás se favorece el gasto inmediato en detrimento del realizable a futuro. Puesto en otros términos, las tasas bajas de interés no parecen tener impacto duradero en reavivar la demanda por

trativo, en la plataforma política del presidente electo de Francia (Emmanuel Macron) se propone reducir de 33.5 a $25 \%$ el Impuesto a la Renta a las empresas.

2 En la práctica esa tesis suprimiría límites al enriquecimiento y restaría protección social a los pobres, como se ha observado empíricamente en casi todos los países. 
cuanto no multiplican por sí mismas las oportunidades de inversión, ni necesariamente vencen las resistencias al gasto de las familias. Con todo, han ayudado a paliar las crisis, rescatar las empresas privadas y, en el caso de los países en desarrollo, a facilitar su financiamiento. En todo caso, la insuficiencia del enfoque monetarista obliga a completar o corregir las políticas anticrisis y a esperar la formación de nuevos liderazgos con China, Alemania o Estados Unidos a la cabeza.

\section{b) La hipótesis del desarrollo exportador}

Las estrategias de crecimiento hacia afuera como sostén del desarrollo comienzan a manifestar debilidades. De un lado, crean desequilibrios acumulativos, acaso insostenibles, entre las balanzas de pagos de los países. Aún economías tan sólidas como la de Estados Unidos, resienten déficit que oscilan entre 500 y 700 miles de millones de dólares anuales, esto es, desajustes que han hecho de ese país la economía más endeudada del mundo. Ha ocurrido aquí un cambio drástico de realidades: de la escasez mundial de dólares de los primeros años de la posguerra se ha transitado a la superabundancia de dólares, de los superávit a los déficit de la economía norteamericana.

De otro lado, las exportaciones al compensar la cortedad nacional de poder adquisitivo de los países superavitarios y hacer lo contrario en los países deficitarios, suelen crear problemas distributivos. Con la globalización, el empleo va a las zonas de mano de obra barata y lo debilita en los países de mano de

Los grandes obra mejor remunerada. Asimismo, buena parte de las economías exportadores tratan de en desarrollo se rompen sus cadenas productivas en formación y se controlar los costos salariales por razones integran otras globales en los segmentos de mano de obra de bajas remuneraciones o en la producción poco elaborada de materias primas. Por su parte, los grandes exportadores tratan de controlar de competitividad los costos salariales por razones de competitividad internacional. A internacional ello se añaden la alta movilidad geográfica de los capitales y la baja movilidad de la mano de obra para afectar la distribución factorial del ingreso y, además originar ondas de inestabilidad con la subvaloración o sobrevaluación resultante de las monedas.

Aparte de los mencionados factores desequilibradores del intercambio mundial de mercaderías, hay otros más que parecen estar en gestación. Si Estados Unidos decide abatir deliberadamente sus desajustes comerciales por fuerza generará limitaciones al comercio, sobre todo al de algunos países. A mayor abundamiento, la madurez económica alcanzada por China y en menor grado por la India, ya comienza a auspiciar ciclos internos de sustitución de importaciones de bienes tecnológicamente más y más complejos en detrimento de los intercambios mundiales, tendencias, además, estimuladas por el abatimiento presente de las transacciones internacionales.

Esos hechos y perspectivas se expresan o se expresarán en ascenso lento o reducción de las transacciones internacionales. El comercio pierde fuerza desde 2008 hasta quedar por debajo de la evolución del producto mundial. Surge así, una suerte de neomercantilismo donde los estados procuran exportar y, a la vez, compri- 
mir importaciones. En esencia, el intercambio deja de ser factor primario de impulso a la producción, mientras crea desajustes comerciales y distributivos. En términos geopolíticos, a ello se suma o sumará la acción de bloques defensivos o enfrentados de países, como resultado de la sustitución del comercio universalmente libre por convenios pragmáticos, frecuentemente bilaterales, que tipifican la vuelta al mundo multipolar (Stiglitz, J. y Yasu, H., 2003, Amsden, A., 2001, Ibarra, D., 2014).

Hoy en día, esos problemas parecen alimentar fenómenos políticos divergentes. Estados Unidos ha anunciado su retirada de la "Transpacific Partnership" a la que quizás siga la de la "Transatlantic Trade and Investment Partnership" con Europa. La trascendencia de esos arreglos residía en asegurar a la economía más importante del mundo, el compromiso multinacional de sostener un régimen ampliado de apertura, guarecido en tratados internacionales casi inamovibles con reconocimiento de su liderazgo. ${ }^{3}$

Con la reducción del dinamismo del comercio hay riesgo de que le siga el del financiamiento a pesar de la enorme liquidez internacional. En el pasado inmediato, los bajos intereses de la deuda externa y, como se ha dicho, la alta liquidez, favoreció el financiamiento al desarrollo. En el caso latinoamericano confluyó la sustantiva reducción de los coeficientes de deuda en el periodo 2003-2008, asociados al auge internacional de las materias primas. Dichos factores podrían comenzar a revertirse, entre otros, por el alza de las tasas de interés de la Reserva Federal. 4

La balanza mexicana de pagos no escapa a esa situación de inestabilidades. Desde 1997, la tasa de crecimiento del comercio se abate al agotarse los impulsos iniciales del TLCAN. Además, la excesiva concentración del intercambio con Estados Unidos resultará doblemente riesgosa si su gobierno se inclinara por implantar prácticas defensivas de su balanza de pagos. Además, hay factores agravantes: las exportaciones nacionales son predominantemente maquilas a lo que se suma el desplome de las colocaciones petroleras.

3 El TPP (por sus siglas en inglés) ensancha sustancialmente los compromisos de apertura de los países signatarios en temas como barreras no arancelarias y contenidos nacionales de producción, reglas de origen, derechos de propiedad, comercio digital, estándares de trabajo, regulación de empresas públicas, medio ambiente, solución de controversias, entre otros asuntos. A ello se añaden la suscripción de obligaciones en torno al manejo macroeconómico de los países, destacando la de evitar la desalineación persistente de los tipos de cambio y las devaluaciones competitivas. El TPP es un convenio abierto a la incorporación de nuevos países, aunque sujeto a la aprobación de cada uno de los miembros anteriores. El interés norteamericano se expresaba en formar nuevos compromisos en el grado de apertura de los países congruentes con las tesis norteamericanas sobre la integración de la economía mundial y quizás en el fortalecimiento de sus ventajas en productos de alta tecnología y, en general, en la protección de los derechos de propiedad. De su lado, los países en desarrollo tendrían el interés de ganar acceso seguro sobre todo al mercado estadounidense. En este terreno, los beneficios potenciales acaso resultarían menores o más competidos en el caso de México y Canadá que ya cuentan con los accesos del Tratado de Libre Comercio de América del Norte (TLCAN).

4 A título ilustrativo, el Fondo Monetario Internacional, al medir los flujos alimentadores del balance financiero latinoamericano, registra cifras negativas de 140 miles de millones de dólares anuales entre 2008 y 2015. En contraste, en el periodo 1999 y 2008, sólo la transferencia de ahorros privados alcanzó los 46 miles de millones de dólares positivos por año. 
El paradigma del desarrollo exportador encuentra escollos en su eficacia desarrollista para convertirse más y más en un juego de suma cero
Según el Banco de México, el superávit de comercio de bienes con Estados Unidos suma alrededor de 120000 millones de dólares anuales (10\% del producto mexicano). No obstante, esa cifra, el déficit global de la balanza de pagos empeoraría si se confirma la renegociación del Tratado de Libre Comercio de América del Norte. Veamos con más detalle esta cuestión: el superávit con Estados Unidos es alto; en los dos últimos años se ha devaluado alrededor de $50 \%$ el peso mexicano; además, la tasa de crecimiento del producto $-y$ por tanto de las importaciones - se ha reducido substancialmente de compararse las últimas cifras con las del periodo de prosperidad 1946-1970; México es un país muy abierto, con múltiples acuerdos de libre comercio. Aun así, el desajuste de la balanza de pagos es del orden de $3 \%$ del producto y de $1.5 \%$ el comercial.

La fragilidad de las cuentas externas nacionales ofrece pocas opciones de acción inmediata: o se atrae capital foráneo, aunque sea inversión volátil de cartera (ya hay 116 mil millones de dólares) o se reprime la tasa de crecimiento nacional como vía de limitar las importaciones y los desajustes consiguientes. ${ }^{5}$ Por lo demás, diversificar y afianzar los mercados a donde potencialmente se podría vender, es un objetivo inexcusable, pero que difícilmente podría concretarse en tiempos breves. 6

Así, el paradigma del desarrollo exportador encuentra escollos en su eficacia desarrollista para convertirse más y más en un juego de suma cero, singularmente frente al posible renacimiento de inclinaciones proteccionistas en el mundo. Otro tanto comienza a ocurrir en otras dimensiones de la acción de los gobiernos, como ocurre en materia fiscal o en los pactos que hacían de los mercados de trabajo mecanismos indispensables de conciliación social.

\section{c) Impuestos y competencia}

En cuanto a lo primero, se han sometido a la concurrencia internacional los sistemas tributarios sea para ganar competitividad o atraer inversiones, con abandono de la política fiscal en respaldo a la estabilización del ritmo de desarrollo o de la corrección de desigualdades. La baja en los impuestos directos, la supresión de gravámenes al comercio exterior, el alza de los que inciden sobre las ventas, el empleo y la seguridad social son fenómenos harto generalizados y conocidos (Webber, C. y Wildasky, A., 1986; Hall, R. y Rabushka, A.,1983; Ibarra, D., 2011). Por eso, muchos países adoptan el monetarismo o más recientemente las políticas de la consolidación fiscal, al tiempo que limitan la vía redistributiva de la imposición para centrar esa última función en un gasto público casi siempre reprimido. ${ }^{7}$

5 Los saldos nominales de los valores gubernamentales en circulación en poder de no residentes, de ser $2 \%$ del total a fines de 2001 , ascienden a $36 \%$ (11\% del producto) en 2016 y luego descienden ligeramente en meses recientes.

6 Aunque ya la envergadura de las devaluaciones recientes alentó a algunos sectores exportadores -incluido el turismo- y a cierta sustitución de importaciones, el déficit persiste, si bien se ha reducido ligeramente entre 2015 y 2016.

7 En los países de la OCDE entre 1980 y 2007 las tasas máximas del Impuestos sobre la Renta a las personas se redujeron de 65 a $40 \%$ y las empresariales de 50 a 30\%. De otro lado, los gra- 
La tributación ha dado en considerarse rémora a la competitividad internacional. Con todo, la reducción de los impuestos directos no ha deprimido por entero la captación de ingresos fiscales por el alza extraordinaria de beneficios de empresas y de los sectores de alto ingreso. Aun así, los agobios presupuestarios hacen que el crédito o el ahorro extranjero, se conviertan en sustituto de las erogaciones públicas antes destinadas al empleo o la inversión. Hoy, se modera ese gasto y los déficit de los gobiernos frente a la real o supuesta resistencia ciudadana a tributar. Por eso, la sostenibilidad de la deuda externa, se convierte en preocupación central de los enfoques auspiciados por los organismos financieros internacionales. Aunque las empre-

Los agobios

presupuestarios hacen que el crédito 0 el ahorro extranjero, se conviertan en sustituto de las erogaciones públicas antes destinadas al empleo o la inversión sas evaluadoras de riesgos comienzan a manifestar preocupaciones sobre el nivel y el ascenso reciente de la deuda externa mexicana, todavía parecen existir márgenes amplios de maniobras para facilitar una política fiscal más activa (Casar, J., 2017).

Sea como sea, esas tendencias reducen las vías de democratización popular de la tributación y de los presupuestos públicos (Goñi, E. et al., 2008; Genschel, P. y Schwartz, P., 2012); -tanto del lado de los ingresos como del gasto - al coincidir, además, con los salvamentos bancarios y las acciones contracíclicas en buen número de naciones. ${ }^{8}$ Adviértase que, sin tocar los impuestos, el equilibrio fiscal sólo puede satisfacerse acomodando o reprimiendo el gasto, esto es, implantando una austeridad pública más o menos permanente. $Y$ en esa tesitura lo más fácil de reducir son las erogaciones que van a la formación de capital o a cubrir demandas sociales, con daño posible al desarrollo futuro. En la práctica, el nivel, la estructura del gasto y de los gravámenes públicos reflejan nítidamente las preferencias de los gobiernos y de sus elites.

México no escapa a la evolución descrita, magnificada por el derrumbe del doble aporte petrolero a las finanzas nacionales (alrededor de 30\% de los ingresos federales hasta antes de la última crisis) y a la balanza de pagos (entre 43000 y 18000 millones de dólares anuales de 2008 a 2015). Por esas y otras razones, los ingresos tributarios desde la década de 1970 oscilan apenas entre 10 y 12\% del producto, compensados en los últimos ejercicios con imposición indirecta del Impuesto Especial sobre Productos y Servicios (IEPS) a los energéticos. Ahí reside la razón estructural de la menguada inversión pública, del rezago en los derechos sociales y del recorte reciente de los gastos gubernamentales para enfrentar desajustes con el exterior. ${ }^{9}$

vámenes a las ventas y los relacionados con el trabajo, explican $70 \%$ del aumento de la carga tributaria en los países de la OCDE en el periodo 1980-2013. En México la reducción de las primeras fue de 55 a $28-32 \%$ y las de las segundas de $40 \%$ a $28-32$ por ciento.

8 Por ese motivo la deuda gubernamental ha crecido considerablemente en los países industrializados. Así en el periodo 2007-2013 pasó de 60 a 107\% del producto en Estados Unidos, de 66.5 a $95.7 \%$ en el área del Euro y de 183 a 243.5\% en Japón.

9 La formación pública de capital, decrece a razón de $6.3 \%$ anual entre 2010 y 2015, hasta representar una fracción anormalmente baja de su aporte al ensanchamiento de la infraestructura nacional (sólo 3.7\% del producto en 2015). 


\section{d) La precariedad de los mercados de trabajo}

En cuanto al empleo, la competitividad internacional abierta ha debilitado las funciones de los mercados nacionales de trabajo como armonizadores históricos de los intereses de empresarios y trabajadores. A través de ese mecanismo, los trabajadores se obligaban a aceptar la disciplina empresarial sin exagerar peticiones, crear agitación política, ni transformar su descontento en descomposición social, mientras

La estructura del gasto y

de los gravámenes públicos reflejan nítidamente las preferencias de los gobiernos y de sus elites los empresarios garantizaban junto con los gobiernos, el empleo y la protección social de la mano de obra.

Dicho ingrediente de los pactos sociales fue debilitado por la globalización al romper el equilibrio entre demanda y oferta de empleos en el mundo (Rodrik, D., 2017). En efecto, entre 1980 y 2000, la fuerza de trabajo incorporada a los mercados abiertos casi se duplica, sube de 1500 a 2900 millones de personas, dejando muy corta a la demanda de ocupaciones. Otro efecto, consistió en la depreciación o estancamiento de las remuneraciones salariales de los países industrializados y de desarrollo intermedio (Freeman, R., 2008; Ibarra, D. (2017). A lo anterior, se añaden otros fenómenos socio-demográficos, donde destaca la sustancial incorporación de la mujer como demandante de trabajo. De ahí que no resulten sor-

Los beneficios del ascenso de la productividad favorecen mucho al capital; el sindicalismo se abate, hay pérdida de influencia política de los trabajadores y ganancia de los segmentos sociales altos en la orientación de las políticas socioeconómicas presivos los acrecentamientos del desempleo crónico o el rezago salarial en los países industrializados, junto al ascenso explosivo de la informalidad en muchas zonas comparativamente atrasadas (OIT, varios números). 10

El empleo mundial ha resultado afectados por esos fenómenos. En general, el ritmo de ampliación de las ocupaciones en las naciones industrializadas ha caído más de $50 \%$ de compararse el periodo 2001-2006 con los años posteriores a la crisis de 2008 (de 0.9 a $0.4 \%$ anual) mientras se mantiene alrededor de $2 \%$ en el Sudeste Asiático y con mayores oscilaciones en América Latina. En esos procesos también tiene papel destacado el avance tecnológico que desplazan empleo de las actividades susceptibles de ser automatizadas o sustituidas por el abaratamiento de los bienes de capital. ${ }^{11}$ Al propio tiempo, influyen las fallas de correspondencia entre las ofertas de profesionistas o de trabajadores calificados de los sistemas educativos y la demanda de los sectores productivos. En esencia, sin embargo, lo que más ha contado hasta ahora son los masivos desplazamientos geográficos de la actividad productiva.

10 En Europa la desocupación abierta oscila entre 9 y $10 \%$ de la fuerza de trabajo. De su lado, la informalidad se estima en más de 1000 millones de trabajadores en las zonas de desarrollo. En Estados Unidos la desocupación se reduce, pero los salarios de la mano de obra hasta ahora no se recuperan plenamente. También en Norteamérica el proceso de recuperación del empleo después de 2008 ha proseguido hasta casi normalizarse. Sin embargo, no ha ocurrido lo mismo sectorialmente, donde, por ejemplo, la participación de la industria en el empleo no agrícola, ha caído de una cifra de $30 \%$ en buena parte de la posguerra a menos de $12 \%$ en la actualidad, siguiendo la involución industrial que, de alcanzar 24\% del producto en 1970, cae en 2015, a sólo 12 por ciento.

11 El cambio tecnológico -uso del internet- ya afecta al sector de servicios reduciendo el empleo en actividades al menudeo y en la preparación de información periodística. 
Por supuesto, los cambios en los mercados de trabajo no se restringen a su impacto cuantitativo, tienen profundas repercusiones cualitativas: los salarios pierden peso frente al ascenso de las remuneraciones al capital; se reduce la participación de los trabajadores en el producto de los países, en casi todas las latitudes; 12 los beneficios del ascenso de la productividad favorecen mucho al capital; el sindicalismo se abate. El corolario es inescapable, hay pérdida de influencia política de los trabajadores y ganancia de los segmentos sociales altos en la orientación de las políticas socioeconómicas que guarecían históricamente, por ejemplo, en Estados Unidos, la estabilidad distributiva (Ibarra, D., 2017; Cameron, D., 1982; Lavoie, M. y Stockhammer, E., 2013; Elsby, M. et al., 2013).

En México, el empleo informal absorbe alrededor de 50 a $60 \%$ de la fuerza de trabajo. Por eso, el desempleo abierto (4 y 5\%) es bajo, además de carecerse de seguros de desempleo; la válvula de escape de la emigración se ha reducido notablemente en el último quinquenio, dejando como residuo a la numerosa población indocumentada (10 millones) que vive en Estados Unidos; 13 la sindicalización y la influencia de las principales centrales obreras van a la baja; los salarios se precarizan y la participación de los trabajadores en el producto se ha reducido de 46 a $28 \%$ entre 1946 y 2013;14 pobreza de diversa naturaleza e intensidad afecta a $50 \%$ de la población, mientras $10 \%$ de los ciudadanos mejor situados, se llevan bastante más de la mitad del producto (Atkinson, A., et al., 2011; Piketty, T., 2014; Piketty, T. and Saez, E., 2003; Samaniego, N., 2014).

\section{e) La distribución del ingreso}

Por tiempo limitado a partir del final de la década de los treinta del siglo pasado, mejora la equidad distributiva en Estados Unidos y en buen número de países. Sin embargo, la oleada positiva se revierte con fuerza desde la década de 1970, hasta alcanzar los extraordinarios niveles de desigualdad del siglo XIX, raíz de la Gran Crisis de 1930. El último decil de la población (los ricos) de los países industrializados toman alrededor de $30 \%$ del producto y de $40 \%$ o más si se incluyen los dos deciles más al-

En América Latina los sesgos distributivos son más acusados. En México, ese 10\% de la población rica, toma $60 \%$ o más del producto tos. 15 Por supuesto, en América Latina los sesgos distributivos son más acusados. Por ejemplo, en México, ese $10 \%$ de la población rica, toma $60 \%$ o más del producto (Campos, R., et al., 2016). Visto a la inversa $10 \%$ de los más pobres se lleva alrededor de 3 a $5 \%$ del producto de los países del Primer Mundo y apenas entre el medio y $1.5 \%$ en América Latina a pesar de las transferencias de ingreso de los gobiernos de la región.

12 En México, pasa de 40.6\% en 1976 a $28.1 \%$ en 2008.

13 Ese grupo vive la incertidumbre de la expulsión atribuible a las nuevas políticas del gobierno norteamericano.

14 La producción manufacturera ha dejado de ser la actividad más dinámica del país, como lo atestigua el estancamiento en su aportación al producto entre 2000 y 2015 poco más de $17 \%$. Asimismo, su contribución al empleo formal decae de 19 a $16 \%$ en el mismo periodo.

15 En Estados Unidos, las tendencias a la concentración distributiva son particularmente acusadas, cuando $0.1 \%$ de la población absorbe casi $8.9 \%$ del producto de $2 \%$ que registraba en 1960 . 
Conclusión similar se obtiene siguiendo la evolución de los coeficientes de Gini16 que miden el grado de igualdad o de desigualdad en el reparto del ingreso. En los países industrializados se registran cifras altas o en ascenso a partir de 1980. En buena parte de los casos, los Gini han subido de promedios entre 0.20 y $0.30 \%$ a cifras más altas, singularizándose Estados Unidos (0.41) e Inglaterra (0.38). ${ }^{17}$

La ecuación igualdad-desigualdad tiene múltiples dimensiones, unas se refuerzan, entre sí, otras suelen resultar contrapuestas. Hay desigualdades de ingreso, de género, de grupo social o étnico, de educación, entre otros que afectan de distinta manera al desarrollo de individuos y poblaciones. Entonces, la cuestión central no es la búsqueda de la igualdad general o en abstracto, sino la igualdad precisa que se persigue (Sen, A., 1992). Descartando muchas otras desigualdades, en términos económicos si se quiere estrechos, la concentración de ingresos y la pobreza destacan por sus consecuencias en la formación o deformación de hombres y poblaciones, por ser inseparables de la malnutrición, la enfermedad, el desempleo, la discriminación, que truncan o degradan las capacidades y talentos humanos.

Desafortunadamente ya se ha larvado un serio fenómeno de desigualdad distributiva como el principal desajuste social del mundo. Desajuste característico de una situación keynesiana de cortedad de la demanda que desalienta a la inversión y al crecimiento (Voitchovsky, S., 2008; Ostry, J. et al., 2014). En el periodo 1956-1973 el producto mundial creció casi $5 \%$ anual (4.9\%); pero quizás por los malos distributivos, entre 1973-2012 apenas lo hizo a 3.2\%. El fenómeno ocurre en Estados Unidos, Europa y Japón, situación que se repite en gran parte de las naciones en desarrollo.

Vinculado a la pérdida de dinamismo de la economía mundial, tiene lugar un proceso de desplazamiento de la generación del producto y de las especializaciones regionales. Los países industrializados generaban 65\% del producto mundial (1913), hoy (2017) concentran sólo 49\%, en tanto las economías en desarrollo de aportar $35 \%$, ya lo hacen en más de $50 \%$, con China e India a la cabeza. A escala sectorial, son más acusados los movimientos geográficos. La tasa de expansión mundial de las manufacturas se ha sostenido alrededor de 2.8\% anual en el periodo 1990-2014, pero la estructura espacial ha cambiado radicalmente. En efecto, su ritmo de ascenso en los países avanzados (1.7\%) desmerece frente a 5.9\% de las naciones en desarroIlo, singularmente en China. Subdividiendo en dos periodos 1990-2000 y 2000-2014, se observa, además, descenso en el ritmo de crecimiento de los primeros (de 2.3 a $1.3 \%$ ) y ascenso en el de los segundos (de 5.1 a $6.4 \%$ ). Así, en menos de un cuarto de siglo, se duplica de 18 a $36 \%$ el peso manufacturero de naciones emergentes y en desarrollo (UNIDO, varios números).

Esos movimientos fuerzan el desplazamiento hacia los servicios en muchas economías que no resisten los bajos costos sobre todo los de la mano de obra de los nuevos productores. En Estados Unidos cae drásticamente la participación en el pro-

16 El coeficiente de Gini varía entre 0 y 1. La cifra cero indica una distribución perfectamente igualitaria. El uno señala la concentración absoluta del ingreso.

17 Buena parte de la información tiene por fuente las bases de datos del Banco Mundial y de la CEPAL. 
ducto del sector de las manufacturas de 23.8 a $11.8 \%$ entre 1970 y 2015,18 mientras lo opuesto ocurre en el sector financiero. Pero en la mayoría de los casos, los salarios de los servicios no suelen compadecerse de la bondad de las antiguas remuneraciones industriales. La huida hacia los servicios no es general. En particular, los países que vía ascensos de la productividad han compensado los mayores costos de la mano de obra, no sólo sostenido sin mengua a los sectores manufactureros externos, sino alcanzado ritmos envidiables de desarrollo y consolidación económica. En ese terreno destaca Alemania y buena parte de los tigres asiáticos (Audretsch, D. y Lehmann, F., 2016)

Transformaciones y desplazamientos productivos hacen crecer mucho a algunas

Transformaciones

y desplazamientos

productivos hacen

crecer mucho a algunas economías, mientras otras

se debaten en problemas

graves economías, mientras otras se debaten en problemas graves (América Latina, África, Medio Oriente), incluidas partes del mundo industrializado. El ascenso de China y la India con sus enormes poblaciones ha contribuido a cerrar, que no a borrar, las desigualdades de ingreso entre países. ${ }^{19}$ Pero la globalización no ha servido para reducir, sino para profundizar, las disparidades distributivas al interior de las naciones (Piketty, T., 2014; Cingano, F., 2014; Milanovic, B., 2005). El bienestar humano está lejos de avanzar hacia una igualdad mejor compartida.

En México, la contracción del crecimiento es todavía más intensa. En el primer periodo (1956-1973) el ascenso del producto excede de $6 \%$ anual para comprimirse casi a la mitad en el segundo (1973-2012) y seguir cayendo hasta un tercio de la primera cifra citada. En el año en curso se estima el crecimiento por debajo de $2 \%$ que implica estancamiento o descenso en el ingreso por habitante si se toma en cuanto al crecimiento demográfico y el de la productividad. En cierto modo, el desarrollo nacional parece esfumarse en el tiempo.

\section{f) Los quebrantos democráticos}

Habría sido sorprendente que los requerimientos del orden internacional, los desplazamientos de la producción y la cesión obligada de soberanía, no tuvieran incidencia en la evolución de las democracias nacionales al validar la libertad de mercados sobre casi cualquier otro criterio. Por esa misma razón, los conflictos distributivos surgen hoy en día de problemas al interior de los países más que de tensiones propiamente internacionales.

Sin duda, los armazones democráticos nacionales se han fortalecido formal e institucionalmente en cuanto a la organización independiente de los procesos elec-

18 Lo mismo ocurre en el conjunto de los países industrializados, donde la tasa de participación de las manufactureras en el producto cae a razón de 4.8\% anual en el periodo 2000-2015. De la misma manera, mientras el crecimiento anual del valor agregado manufacturero en los países de la OCDE fue de $10 \%$ en ese periodo, en China lo hizo a $300 \%$ y en otras economías en desarrollo a 59\%. La migración geográfica de la producción manufacturera es considerable como lo atestiguan las cifras anteriores. En México el peso del valor agregado manufacturero está estancado (alrededor de $17 \%$ del producto).

19 El ingreso por habitante de países muestra todavía diferencias abrumadoras. Mientras Noruega, Suiza, Suecia, Qatar, alcanzan cifras hasta dos veces superiores al nivel de Estados Unidos, otras naciones tienen menos de $2 \%$ de dicho nivel (Cambodia, Kenia, Nepal, Haití, Corea del Norte, Etiopía, etc.). 
torales, la división de poderes, la observancia de los tratados internacionales y el financiamiento de los partidos políticos. Pero ha de reconocerse un componente rezagado, el relativo al ejercicio de la soberanía popular. Ello se manifiesta en otorgar poca prelación a las demandas y aspiraciones de las poblaciones, frecuentemente contrariadas por las reglas de la globalización.

Al quedar los sistemas políticos nacionales limitados por criterios tecnocráticos o de orden global, surgen déficit democráticos expresados en desánimo político y hasta desconfianza en la misma democracia. Singularmente desde 1970, hay caída en el volumen de votantes, aún en los comicios de las potencias líderes (Francia, Alemania, Inglaterra, Estados Unidos y Canadá) y multiplicación de elecciones poco concurridas. Al propio tiempo, es bastante general la reducción de la membresía de los partidos políticos en relación al tamaño de los electorados, mientras los comicios se tornan volátiles, propensos al populismo de cualquier signo, no afianzados en posturas ideológicas firmes de los propios partidos. La desigualdad y la debilitada voz popular erosionan la solidez de la vida política en tiempos, donde, como reacción paradójica, ganan respaldo ciudadano los derechos humanos (Dalton, R., 2004; Van Biezen et al., 2011; Schmitter, P., 2001).

Los sistemas políticos nacionales al quedar limitados por criterios tecnocráticos o de orden global, dan lugar a déficit democráticos expresados en desánimo político

y hasta desconfianza en la misma democracia
El desencuentro entre democracias nacionales y globalización, entre democracia y economía, se expresa en desigualdades, que reflejan o se traducen en resquebrajamiento de los pactos sociales, pérdida de legitimidad de los gobiernos, descomposición social y sorpresas electorales mayúsculas. Como se dijo, la distribución universal del bienestar reconoce convergencia con la expansión acelerada de los países más poblados, aunque subsista el rezago de muchas otras regiones. Ello, no obstante, valga repetir, donde más intensamente se da el proceso polarizador de ingresos es al interior de casi todas las naciones. Así lo muestran, las cifras de Estados Unidos, Inglaterra, China, México y Chile. En algunos casos incluso ha podido hacerse retroceder la pobreza, pero persiste y aún se agrava la desigualdad. Por razón natural, entonces, la magnitud de las reacciones críticas, se expresan con mayor intensidad en los países con los sistemas democráticos mejor afianzados.

La magnitud de las reacciones Los inesperados resultados de comicios y plebiscitos seguracríticas, se expresan con mayor mente tendrán consecuencias y crearán inestabilidades en la confiintensidad en los países con los guración de sus políticas y hasta en el orden económico internaciosistemas democráticos mejor nal. El Brexit, el triunfo de Trump o las significativas derrotas del PRI afianzados en las pasadas elecciones intermedias de México, tienen denominadores comunes, expresan la insatisfacción de amplios grupos sociales agobiados por el abandono, la pobreza y la corrupción en protesta antielitista.

Hasta hace poco las elecciones y el debate entre los partidos políticos estuvieron dominados por temas sobre mercados, productividad e inflación sin mostrar mayor preocupación por condiciones de vida de pobres y clases medias. Tal visión es hoy insuficiente, habrá que incorporar los efectos distributivos de las políticas públicas o de su ausencia en los diversos grupos de electores. 
En la explicación de los rezagos democráticos, no son inocentes las prácticas políticas del último tercio del siglo pasado. Por lo general, angostaron la capacidad decisoria nacional y la respuesta de las políticas públicas a demandas ciudadanas crónicamente insatisfechas. Y todo ello ocurre, en ausencia de arreglos internacionales supletorios o correctores de los déficit democráticos asociados al esquema de la libertad global de mercados.

\section{Conclusiones}

de los países han visto empequeñecer su antigua eficacia socio-política o generado dilemas imprevistos donde destaca el de la igualdad (Dahl, R., 1994; Ibarra, D., 2017). Hoy, es incierto el liderazgo futuro y la dirección de los cambios que se imprimieron al orden internacional. Y a escala nacional, lo es también la delimita-

Han quedado en entredicho las estrategias exportadoras,

las fiscales 0 las de la conciliación social provista antes por los mercados de trabajo y los estados de bienestar. Quiérase o no ha llegado el momento de revisar ideas y creencias
Como se ha examinado, las ideas que orientaron el desarrollo institucional y político de gran parte ción de los papeles de la democracia y de la economía, del mercado y del Estado, de la jurisdicción de las políticas nacionales y de las del orden internacional. Al propio tiempo, han quedado en entredicho las estrategias exportadoras, las fiscales o las de la conciliación social provista antes por los mercados de trabajo y los estados de bienestar. Quiérase o no ha llegado el momento de revisar ideas y creencias.

No sólo los principales modelos reguladores de las economías y de las sociedades muestran vacíos, signos de inadecuación. Lo mismo ocurre en la renovación necesaria de otras muchas visiones envejecidas. Quizás un llamado de atención proviene de la reorientación de los bancos centrales de variados países industrializados (Japón, Unión Europea) que, de combatir a toda costa la inflación, procuran ahora alentarla en cierto grado y hasta combinar el monetarismo con una política fiscal más activa. 20 Del mismo modo, el calentamiento global y la dependencia de combustibles fósiles, pronto tendrán que ser sustituidos por el desarrollo de energías limpias por más que ello conlleve altos costos

Las principales instituciones del orden internacional parecen debilitadas en sus funciones $y$ cometidos sobre todo en los grandes países consumidores y en los petroleros.

Asimismo, las principales instituciones del orden internacional parecen debilitadas en sus funciones y cometidos. Entre otros problemas, el anticuado sistema de votación del Consejo de Seguridad de las Naciones Unidas le impide lograr consensos o lanzar iniciativas medulares sobre problemas críticos del mundo y ha debido reforzarse hasta cierto punto con los acuerdos del G20. La Organización Mundial del Comercio ha visto fracasar su última rueda de negociaciones sobre el intercambio de productos agrícolas y ahora enfrenta la proliferación de tendencias proteccionistas y cierta beligerancia en el manejo de los tipos de cambio. El Fondo Monetario Internacional no ha abordado la doble obligación de ajuste no sólo de los países deudores, sino de los

20 En las noticias económicas de la OCDE del 23 de marzo del año en curso, se indica que "la economía global mejorará modestamente en 2018" alentada por las iniciativas fiscales de las principales economías. 
acreedores, para prevenir y limpiar -como lo propuso Keynes hace años- desequilibrios comerciales insostenibles, singularmente cuando la economía norteamericana ha pasado de acreedora a deudora. En el propio FMl y el Banco Mundial tampoco han otorgado la debida representación e influencia a las potencias emergentes (China, India, Brasil, etc. ${ }^{21}$ y, de otro lado, establecen condicionalidades rigurosas, acaso ideologizadas, a sus préstamos con fines de desarrollo, de salvamento bancario o de corrección de las crisis de pagos. El déficit democrático de la Unión Europea no ha sido llenado dentro del esquema de la integración regional por más poder económico que se haya centrado en Bruselas o en el Banco Central Europeo. Europa padece los inconvenientes de una globalización, integración que ha erosionado tanto a sus estados benefactores como acentuado las diferencias económicas entre sus países miembros del Norte y del Sur. Aún no se admite sanear a economías extremadamente endeudadas con rebajas a sus pasivos internacionales, como lo atestiguan los repetidos salvamentos fracasados de la economía griega. A fin de cuentas, la unión económica, necesita del avance paralelo de la unión política, casi siempre resistida

Suelen hacerse recortes del lado del gasto a fin de satisfacer las exigencias del presupuesto equilibrado y de la contención de la deuda pública por las elites nacionales, cualesquiera que sean (Kotz, H., 2017).22

Hoy el neoliberalismo intenta predeterminar la evolución de las finanzas públicas y hasta las funciones gubernamentales a través de las reglas de la consolidación fiscal. En tanto prevalezca competencia tributaria, se excluyen o evitan las alzas de gravámenes. Más aún, toman cuerpo reformas reductoras de los impuestos a los contribuyentes de alto ingreso con la esperanza de alentar inversión y crecimiento. 23 En esas circunstancias y frente a los usuales desajustes macroeconómicos, suelen hacerse recortes del lado del gasto a fin de satisfacer las exigencias del presupuesto equilibrado y de la contención de la deuda pública. Se justifican, entonces, políticas de austeridad que suelen dificultar el progreso económico y alimentar nuevos ciclos de astringencia gubernamental. Además, dado el crecimiento de las deudas públicas empujado por los rescates bancarios y las políticas contracíclicas a partir de 2008, se reconoció la existencia de riesgo crediticio de los pasivos incluso de los gobiernos. De ahí la preocupación sobre la sustentabilidad de la deuda

21 De ahí el proyecto chino de crear el Banco Asiático de Inversión en Infraestructura al que se han unido numerosos países industrializados o en desarrollo (Francia, Alemania, Canadá, Inglaterra, Australia, Corea del Sur). De la misma manera, la Agencia Internacional de Energía enfrenta tensiones al excluir de su membresía, desde 1974, a grandes países consumidores como China o la India.

22 En el sentido anotado, la plataforma política de Macron, presidente electo de Francia, contiene planteamientos que fortalecerían el Federalismo y la democracia integracionista de Europa. Simplificado, propone crear un presupuesto conjunto para el suministro de bienes públicos, manejado por un ministro responsable frente al parlamento europeo; quiere persuadir a Alemania de usar sus márgenes fiscales en beneficio de Europa para reducir sus enormes excedentes de balanza de pago; reabrir el debate sobre el respaldo recíproco a los pasivos financieros del sector público de la eurozona. Mejorar la coordinación fiscal y la protección del mercado europeo, incluidas respuestas a la política norteamericana de "buy american".

23 Como parece ser la iniciativa anunciada del presidente Trump que provocará presiones en el mismo corte en muchos otros países. 
en países pequeños o en desarrollo, preocupación que recogen prontamente los organismos financieros internacionales para respaldar las estrategias de austeridad fiscal.

Véase como se vea, el mundo encara resistencias al cambio. Quizás el más arduo, sea el de imprimir cara socialmente amigable a la globalización con libertad de mercados. A escala mundial habría que dar comienzo al combate a la insuficiencia artificial de ingresos de grandes segmentos de las sociedades en tanto pone en riesgo la sana convivencia política. Y ello tendría que lograrse en condiciones difíciles, frente a tradiciones, intereses y estadios de desarrollo muy diversos de los países. La tarea ofrece, por tanto, múltiples aristas.

En términos ideales, con baja probabilidad, tal como se hizo al emprenderse la apertura universal de fronteras, cuando se ajustaron los más encontrados puntos de vista y legislaciones, ahora la tarea sería la de reformar el orden internacional para imprimir fuerza legitimadora a los derechos humanos, como garantía mínima de equidad

Los salarios y el empleo debieran acercarse, no alejarse, de ofrecer una vida digna a los trabajadores dentro y en las condiciones de cada país

y de legitimación democrática. A escala nacional, el objetivo consistiría en asegurar a futuro que todos los grupos, clases medias y trabajadores, participen en la distribución de los beneficios económicos o reciban compensación por las dislocaciones de los reacomodos de la producción internacional. A título ilustrativo, los salarios y el empleo debieran acercarse, no alejarse, de ofrecer una vida digna a los trabajadores dentro y en las condiciones de cada país. Los trabajadores que resultasen desempleados o perjudicados por el avance ulterior del libre comercio recibirían de aquí en adelante protecciones apropiadas (Rodrik, D., 2017; Tyson, L., 2017; Colgan, J., Keohane, R., 2017). Las compensaciones podrían variar y comprender desde el fortalecimiento de las políticas de empleo y de ayuda al combate de la desocupación, hasta políticas salariales más activas, impulso a la negociación colectiva, reducción de los impuestos a la nómina y otras medidas favorables a las agrupaciones de trabajadores y clases medias.

De igual manera, el acceso a los servicios básicos de salud y educación habrían de avanzar en ofrecer cobertura universal a toda la población esté o no ocupada. Las políticas hacendarias no caerían invariablemente en la camisa de fuerza de la consolidación fiscal y gravarían por igual, progresiva y acumulativamente los ingresos de los causantes con independencia de sus fuentes. La voz ciudadana habría de ser escuchada en el diseño de las políticas públicas y ser complementada, por ejemplo, con la organización de consejos económicos y sociales que informen y enriquezcan los debates de los poderes legislativos. A escala de las instituciones internacionales valdría democratizarse al Consejo de Seguridad y otros órganos de las Naciones Unidas, así como dar respaldo invariable a los derechos humanos, como medio de emparejar derechos, bienestar e ingresos en las sociedades.

Acercamiento a México

preparado un excelente documento sobre la situación que vive el país. Ahí se plantea la articulación de un plan de contingencia frente a los posibles cambios en las políticas norteamericanas, sea que se enderecen a la adopción de posturas proteccionis- 
El mundo y el país están obligados a ofrecer respuestas con fines de negociación y de alivio a sus efectos adversos en economías y sociedades tas, limiten los derechos migratorios o se traduzcan en trabas a los flujos de inversión hacia México. En ese terreno se analizan posibles cambios en el orden económico internacional, así como la renegociación del Tratado de Libre Comercio de América del Norte. El propósito estadounidense seguramente gira en torno a la reducción de sus desajustes comerciales. Frente a esas cuestiones, el mundo y el país están obligados a ofrecer respuestas con fines de negociación y de alivio a sus efectos adversos en economías y sociedades.

Ante los apremios de la posible alteración de las reglas internacionales de convivencia y las innegables deficiencias de nuestro modelo de desarrollo, será aconsejable mejorar el contenido, las bases mismas de las estrategias económicas del país, aprovechando en esencia las fuerzas propias, esto es, las asociadas a la defensa del desarrollo nacional y de la legitimidad política que surja de una protección social menos sesgada.

Por un lado, cabe observar que la economía internacional, aparte de recuperarse lentamente de la crisis de 2008, arrastra tensiones y no escapa a cambios que pueden resultar desfavorables por largo tiempo a nuestros países. En consecuencia, habrá que prepararse frente a ese escenario incierto, ominoso.

De otro lado, experiencias decantadas en años de aciertos y Cuando el desarrollo se errores, llevan a conclusiones críticas insoslayables. Como el desaesfuma, Estado y mercado rrollo se esfuma en nuestro país, Estado y mercado ya no podrán

ya no podrán ni podrían ni podrían ser primordialmente excluyentes, sino más y más comser primordialmente plementarios. El fortalecimiento de la demanda interna y del tejido excluyentes, sino más y más productivo nacional, por ser indispensables al crecimiento y a una complementarios distribución razonablemente equitativa, debieran recibir la prelación antes otorgada casi por entero a la estabilidad de precios. Acercarse a ese propósito implicaría desplegar políticas industriales activas, selectivas, respaldadas por el sector empresarial y por inversiones públicas, crédito y fomento promocional de la banca de desarrollo. En una palabra, se trataría de formar la agenda e integrar a las instituciones ordenadoras de un Estado moderno, decididamente desarrollista. Por igual, enriquecer nuestra democracia y la misma legitimidad gubernamental, obligaría a revisar los enfoques salariales y del empleo a fin de detener, tanto su estancamiento, como la concentración ulterior del ingreso y perfeccionar los accesos a los servicios públicos básicos, de salud y educación. Esto último obliga a revisar la estructura del gasto público y del catálogo de incentivos fiscales. Aún si las condiciones macroeconómicas imponen límites estrechos a las erogaciones y al endeudamiento públicos, se podría alentar el gasto privado sea por la vía salarial o por la de facilitar y orientar el crédito productivo y de formación de capital del Banco Central y de las bancas pública y privada. También cabría desincorporar cuidadosamente algunas obras públicas con el fin exclusivo de financiar nuevas inversiones de infraestructura del propio sector público. En conjunto, se buscaría poner coto a tendencias económicas depresivas al tiempo que se detiene la polarización del ingreso.

Otro ingrediente necesario del futuro "Estado Desarrollista" consistiría en la renovación del pacto fiscal. Se buscaría subsanar el estrangulamiento derivado del 
derrumbe petrolero, avanzar en mejorar la distribución de las cargas tributarias y corregir rezagos evidentes. Crear entonces un Consejo Fiscal, debiera verse como un instrumento democrático a fin de liberar recursos canalizables a la inversión y a la protección social al tiempo que se imprime mayor progresividad al gasto público y a la propia estructura impositiva.

Superar la crisis y enderezar la economía a una etapa de desarrollo menos pausado, dependerá esencialmente de la capacidad de reorganización de las fuerzas nacionales, privadas y públicas. Todo indica que del exterior se recibirán estímulos disminuidos y probablemente se deban sufragar costos inevadibles

Superar la crisis y enderezar la economía a una etapa de desarrollo menos pausado, dependerá esencialmente de la capacidad de reorganización de las fuerzas nacionales, privadas y públicas sobre todo si se imponen nuevos parámetros al orden económico internacional.

Por supuesto, enmendar las estrategias básicas de desarrollo tendrá costos de adaptación sin mencionar los vinculados a la articulación de los grandes objetivos nacionales: estabilidad de precios sí, pero también crecimiento y empleo. Habría que aceptar mucho mayor liderazgo estatal y quizás asimilar ajustes transitorios de precios, aparte de la absorción de los ya asociados a las significativas devaluaciones cambiarias. Quizás habría que imprimir flexibilidad al tipo de cambio y dejar de considerarlo eje imprescindible del equilibrio económico. El manejo de la política de tasas de interés difícilmente se justificaría en el futuro por razones exclusivas de atraer ahorro foráneo de corto plazo, sin escrutinio de sus implicaciones en la inversión y las cuentas públicas. La competitividad internacional más que en salarios siempre bajos, tendría que fincarse en el fomento orgánico de la innovación, de la incorporación del progreso técnico y sobre todo del perfeccionamiento del tejido productivo interno. Por eso, al inicio de la política industrial tendrá que ser selectiva e incorporar compromisos firmes con los sectores empresariales. Al propio tiempo, podría ser necesario revisar algunos de los tratados de libre comercio y emprender negociaciones difíciles con los países donde se concentran nuestros desequilibrios

La competitividad internacional más que en salarios siempre bajos, tendría que fincarse en el fomento de la innovación, la incorporación del progreso

técnico y sobre todo del perfeccionamiento del tejido productivo interno comerciales (China, Alemania, Corea, Taiwán) no sólo en materia comercial, sino sobre todo de inversión equilibradora.

Dada la gravedad e incertidumbre de una coyuntura que se alarga y lo complejo de las tareas de reorientación del desarrollo, acaso fuese conveniente que el Congreso de la Unión organice una conferencia política de alcance nacional que examine los términos del programa de emergencia y los alcances de la reorientación de la política económica y social. Vale reconocer que ha periclitado la vía cómoda de calcar, siguiendo algún consenso foráneo, las políticas vertebrales de nuestra sociedad. No se trataría tampoco de volver a fórmulas del pasado por más exitosas que hubiesen sido. Idealmente habrá que impulsar un desarrollismo decidido, independiente, más congruente con nuestros intereses de largo plazo frente a los enormes cambios registrados en el mundo y en nuestro país. Para eso, habría que incorporar a los planes de gobierno, ideas nacidas de nuestra realidad, de nuestras carencias y aspiraciones, con el propósito de subsanar el olvido de lo social, resultado del maridaje no regulado de mercados libres y globalización. 


\section{Bibliografía}

Amsden, A. (2001), The Rise of the Rest, Oxford University Press, N. York;

ANDERSON, P. (2015), American Foreign Policy and its Thinkers, Verso, Londres;

AtKInson, A., et al (2011) "Top Incomes in the Long Run of History", Journal of Economic Literature No.

49-1, pp. 3-71;

AudRETSCH, D. y LeHMANN, F. (2016), The Seven Secrets of Germany, Oxford University Press, Inglaterra;

BRESSER-PEREIRA, L., et al (1993), Economic Reforms in Neo Democracies, Cambridge University Press;

CAMERON, D. (1982), Social Democracy, Corporatism and Labour Evanescense, Stanford University, California;

CAmpos, R., et al (2016), Estimating Top Income Shares Without Tax Return Data: Mexico since the 1990's,

Centro de Estudios Económicos, El Colegio de México, México.

CASAR, J., (2017), "Deuda y política fiscal en México" Revista de Economía Mexicana, anuario UNAM, Universidad Nacional Autónoma de México.

CINGANO, F. (2014), Trends in Income Inequality and Its Impact on Economic Growth, OCDE, Working Paper No. 163 ;

Colgan, J., Keohane, R. (2017) "The Liberal Order is Rigged”, Foreign Affairs, mayo-junio, pp. 36-47.

CONEVAL (varios números), Informe de Evaluación de la Política de Desarrollo Social, México.

DAHL, R. (1994) "A Democratic Dilemma: System Effectiveness versus Citizen Participation”, Political Science Quarterly, Vol. 109 (1);

Dalton, R. (2004), Democratic Challenges, Democratic Choices: The Erosion of Political Support in Advanced Industrial Democracies, Oxford University Press;

ElsBY, M. et al (2013), "The Decline of the U. S. Labor Share”, Brookings Papers on Economic Activity, Fall, pp. 1-63, Washington.

Freeman, R. (2008) "The New Global Market”, Focus, Madison Institute for Research in Poverty, 26 (1), University of Wisconsin;

Genschel, P. y SchwarTZ, P. (2012), Tax Competition and Fiscal Democracy, TranState, Working Paper No. 161, University of Bremen.

GoÑI, E. et al (2008), Fiscal Redistribution and Income Inequality in Latin America, Policy Research Working Paper, No. 4487, Banco Mundial, Washington;

HA-JoON, Ch. (2002), Kicking away the Ladder: Development Strategy in Historical Perspective, Wimbledon, Londres;

Hall, R. y RabushKA, A. (1983), Low Tax, Simple Tax, Flat Tax, Mc-Graw Hill, N. York;

IBARRA, D. (2006), La reconfiguración económica internacional, Facultad de Economía, UNAM, México;

(2011), La tributación en México, Facultad de Economía, UNAM, México.

(2014), Desarrollo evanescente y desprotección social, Facultad de Economía, UNAM, México.

(2017), Mercados abiertos y pactos sociales: democracia arrinconada, por publicarse en el Fondo de Cultura Económica, México.

KoTz, H. (2017) "Germany Will Lose if Macron Fails", Project Syndicate, mayo, 15.

LAVOIE, M. y StockHAMmeR, E. (2013), Wage-Led Growth, Palgrave, Inglaterra;

MILANOVIC, B. (2005), Worlds Apart: Measuring International and Global Inequality, Princeton University Press. 
MINSKY, H. (1986), Stabilizing and Unestable Economy, Yale University Press, N. York;

NYE, J. (2017) "Will the Liberal Order Survive?", Foreign Affairs, Vol. 96, No. 1;

ОІт (varios números), World of Work Report, Ginebra.

OstRY, J. et al (2014), Redistribution, Inequality and Growth, IMF, Staff Discussion.

PATRICK, S. (2017) "Trump and the World Order", Foreign Affairs, Vol. 96, No. 2;

PIKETTY, T. (2014), Capital in the Twenty-First Century, The Belknap Press of Harvard University Press,

Cambridge, Mass;

PIKETTY, T. and SAEZ, E. (2003) "Income Inequality in the United States, 1913-1948”, Quarterly Journal

Economic, 118 (1);

RodRIK, D. (2017) "Too Late to Compensate Free Trade's Losers”, Project Syndicate, abril 11.

(2017) “Too Late to Compensate Free Trade's Losers", Project Syndicate, abril 11;

SAMANIEGo, N. (2014) "La participación del trabajo en el ingreso nacional: el regreso a un tema olvidado",

Revista Economíaunam, No. 33, UnAM, México;

SCHMITTER, P. (2001), "Parties are no What they Once Were", en Diamond y Gunther editors, Political Parties and Democracy, John Hopkins University Press.

SEN, A. (1992), Inequality Reexamined, Harvard University Press, N. York.

StiglitZ, J. y YASU, H. (2003), Rethinking the East Asia Miracle, Oxford University Press, N. York;

STREECK, W. (2014) "Where are we now?", London Review of Books, julio.

TYSON, L. (2017) "The Truth about Nafta", Project Syndicate, abril 4;

UNIDO (varios números), Industrial Development Report, N. York.

VAN BIEZEN et al (2011) "The Decline of Party Membership, Contemporary Europe", European Journal of

Political Research, Vol. 51 (1);

VoITCHOVsky, S. (2008) "Does the Profile of Income Inequality Matter for Economic Growth?", Journal of

Economic Growth, Volume 10, (3);

WebBer, C. y WILDASKy, A. (1986), History of Taxation and Expenditure in the Western World, Simon \& Schuster, N. York;

WILLIAMson, J. (1990) “What Washington Means by Policy Reform?”, In Latin American Adjustment, Institute for International Economics, Washington;

ZAKARIA, F. (2016) "Trump Prepared to Pass the World Leadership Baton to China", The Washington Post, marzo. 